\title{
Compare the efficacy, safety and compliance of oral estradiol and vaginal estriol for urogenital problems in post-menopausal women
}

\author{
Shipra Kumari*, Monika Singh
}

Department of Obstetrics and Gynecology, S. N. Medical College, Agra, Uttar Pradesh, India

Received: 03 January 2020

Accepted: 07 February 2020

*Correspondence:

Dr. Shipra Kumari,

E-mail: sk2258099@gmail.com

Copyright: (C) the author(s), publisher and licensee Medip Academy. This is an open-access article distributed under the terms of the Creative Commons Attribution Non-Commercial License, which permits unrestricted non-commercial use, distribution, and reproduction in any medium, provided the original work is properly cited.

\begin{abstract}
Background: Menopause is recognised to have occurred after 12 months of amenorrhoea for which there are no obvious pathological and physiological causes, it is retrospective diagnosis. Objective of this study was to compare the efficacy, safety and compliance of oral estradiol and vaginal estriol for urogenital problems in post-menopausal women.

Methods: A total of 100 postmenopausal women having urogenital symptoms were selected for the prospective study. The selected patients were randomly allocated in 2 groups. Group A received $2 \mathrm{mg}$ of estradiol OD for 4 weeks and then evaluated after 4 weeks. Group B received $0.5 \mathrm{mg}$ of vaginal estriol cream continuously for 4 weeks at night and then evaluated after 4 weeks. Patients were followed after 1,3 and 6 months. Inclusion criteria were postmenopausal women, vaginal symptoms, urogenital symptoms. exclusion criteria were all patients having estrogen dependent neoplasia and comorbidities.

Results: For urinary complaints, symptomatic relief was assessed by AUA Score in which after 6 months; in Group A the difference in mean from baseline was $19.64 \pm 1.63$ and in Group B it was $21 \pm 2.52$ and was statistically insignificant from each other. For genital complaints, symptomatic relief was graded as 1, 2, 3, 4 in which grade 4 means complete relief. After 6 months of therapy 88.2\% got complete relief in Group A and $91.1 \%$ in Group B. In vaginal cytological smears; in both groups, parabasal cells were reduced and superficial cells were increased after 6 months of therapy and both groups were statistically insignificant from each other. After 6 months of therapy, increase in mean value of KPI from the baseline is $24.54 \pm 10.1$ in Group A and 28.6 \pm 10.11 in Group B and both groups were statistically insignificant. Endometrial thickness remained unchanged in both the groups after 6 months of therapy.
\end{abstract}

Conclusions: Both drugs were equally effective in alleviating the urogenital symptoms with no significant side effects.

Keywords: Estradiol, Estriol cream, Post-menopausal

\section{INTRODUCTION}

Menopause is recognised to have occurred after 12 months of amenorrhoea for which there are no obvious pathological and physiological causes, it is retrospective diagnosis. It occurs due to depletion of ovarian follicle resulting in near complete, but natural diminution of hormone secretion. ${ }^{1}$ The genitourinary syndrome of menopause (GSM) is a new term that describes various menopausal symptoms and signs associated with physical changes of the vulva, vagina, and lower urinary tract. The GSM includes not only genital symptoms (dryness, burning, and irritation) and sexual symptoms (lack of lubrication, discomfort or pain, and impaired function), but also urinary symptoms [urgency, dysuria, and recurrent urinary tract infections (UTI)]. 
The terms vulvovaginal atrophy and atrophic vaginitis were widely used until recently, but they have been considered to be inadequate for referring to the constellation of symptoms and signs associated with the genitourinary system after menopause. The term vulvovaginal atrophy mentions the vulva and vagina only, and these words are not used comfortably in general social discussion and in the media. The term atrophic vaginitis implies a state of inflammation or infection, which is not a primary component of menopausal changes. In addition, a limitation of the terms vulvovaginal atrophy and atrophic vaginitis is that they do not take into account the symptoms of the lower urinary tract, which are among the most important symptoms related to menopause. ${ }^{2}$

Therefore, the Board of Directors of the International Society for the Study of Women's Sexual Health (ISSWSH) and the Board of the North American Menopause Society (NAMS) have acknowledged the necessity of new terminology instead of the terms vulvovaginal atrophy and atrophic vaginitis, and a terminology consensus conference was held in 2013. The ISSWSH and NAMS Boards finally formally approved the term GSM in early 2014.

The word "menopause" (menopause)was used for the first time in 1816 by Gardanne. ${ }^{3}$ Hormone replacement therapy is available in many formulations combination and routes. ${ }^{4}$ Unlike other estrogens, estriol is short acting since it has only a short retention time in the nucleus of endometrial cells therefore, no endometrial proliferation is to be expected when the total recommended dose is taken at one time. Hence, cyclic administration of progestogen is not necessary and post-menopausal withdrawal bleeding does not occur.

Although a number of symptoms have been associated with the transition to menopause, only vasomotor and urogenital symptoms have been shown to be directly correlated with these changing hormone levels. ${ }^{5}$

That's why present study is being placed to find out effective and safe way of treating post-menopausal urogenital symptoms.

\section{METHODS}

The present study was carried out in department of obstetrics and gynecology, S. N. Medical College, Agra. The patients were selected from the outpatient ward in department of gynecology and the patients were postmenopausal women. The duration of study was from October 2015 to December 2017.

\section{Selection of cases}

A total of 100 postmenopausal women having urogenital symptoms were selected for the prospective study.
The selected patients will be randomly allocated in 2 groups

Group A: received $2 \mathrm{mg}$ of Estradiol OD for 4 weeks and then evaluated after 4 weeks.

Group B: received $0.5 \mathrm{mg}$ of vaginal estriol cream continuously for 4 weeks at night and then evaluated after 4 weeks.

\section{Inclusion criteria}

- Postmenopausal women (natural and surgical menopause) with urogenital problems.

- Vaginal Symptoms such as:

- Dryness, discharge, soreness

- Itching

- Dyspareunia

- Urogenital symptoms such as

- Incontinence

- Urgency

- Frequency

- Dysuria

- Nocturia

\section{Exclusion criteria}

- $\quad$ Patient with undiagnosed vaginal bleeding

- Genital neoplasia, breast neoplasia or history of carcinoma breast and carcinoma endometrium in family

- Patient with cardio vascular disease

- Patients with hypertension and diabetes

- Patients with history of jaundice and thromboembolic phenomenon

- Allergic to ingredient of estradiol valerate.

- History of known or suspected breast cancer.

- Any other estrogen dependent cancer

- Having blood disease porphyria, blood clots, liver problem

\section{Follow-up}

Patients were evaluated after one, three and six months, for improvement in,

- Clinical symptoms

- Vaginal pH

- Endometrial thickness

- Karyopyknotic index.

\section{Maintenance dosage}

\section{Group-A}

\section{Evaluation after 1 month}

- $\quad$ After 4 weeks, if getting relief, then dose of estradiol was reduced to half and given OD for next 3 months 
- If getting no relief, same dose of $2 \mathrm{mg}$ was given for next 3 months.

Again, evaluation was done after 3 months

- If getting relief, then estradiol (1 mg) was given twice a week for next 2 months

- If getting no relief, then estradiol (2 mg) was given OD for next 2 months.

\section{GROUP-B}

\section{Evaluation after 1 month}

- After 4 weeks if getting relief, then $0.5 \mathrm{mg}$ of Vaginal Estriol cream was given on alternate nights for next 3 months.

- If getting no relief, the same dose of $0.5 \mathrm{mg}$ was given OD for next 3 months at night

Again, evaluation will be done after 3 months

- If getting relief; then $0.5 \mathrm{mg}$ of vaginal estriol cream was given twice a week at night for next 2 months

- If getting no relief; then $0.5 \mathrm{mg}$ of vaginal estriol cream was given OD at night for next 2 months.

\section{Statistical analysis}

Results of this study have been concluded by mean, standard deviation, proportion.

\section{RESULTS}

In this study, mean baseline AUA score at presentation in Group I was $22.26 \pm 2.82$ while in Group II was $23.26 \pm 3.87$, the difference between two groups was statistically not significant $(\mathrm{p}$ value $=0.1559)$. At 1 month after therapy in both groups mean AUA score was $14.23 \pm 2.51$ and $13.32 \pm 3.23$ in Group I and Group II respectively, the difference between two groups was statistically not significant with $\mathrm{p}$ value of 0.1309 . At 3 months after therapy the mean AUA score was 9.21 \pm 2.34 and 8.21 \pm 3.14 in Group I and Group II respectively, the difference between two groups was statistically not significant with $\mathrm{p}$ value of 0.0836 . At 6 months after therapy the mean AUA score was 3.62 \pm 1.19 and $3.26 \pm 1.35$ in Group I and Group II respectively, the difference between two groups was statistically not significant with $\mathrm{p}$ value of 0.1736 .

Symptomatic relief for vaginal symptoms was graded as $0,1,2,3,4$ in which 0 means no relief $(0 \%), 1$ means slight relief (25\%), 2 means mild relief (50\%), 3 means moderate relief $(75 \%), 4$ means complete relief $(100 \%)$. After 1 month of therapy complete relief was attained by $23.53 \%$ patients $(n=8)$ in Group I and $32.35 \%$ patients $(\mathrm{n}=11)$ in Group II. After 3 month of therapy complete relief was attained by $44.12 \%$ patients $(n=15)$ in Group I and $50 \%$ patients $(\mathrm{n}=17)$ in Group II. After 6 month of therapy complete relief was attained by $91.17 \%$ patients $(\mathrm{n}=31)$ in Group I and $94.12 \%$ patients $(\mathrm{n}=32)$ in Group II.

Table 1: Distribution of cases according to AUA Score (American Urological Score) for symptomatic relief of urinary symptoms.

\begin{tabular}{|ll|lllll|}
\hline AUA Score & Estradiol & \multicolumn{3}{c}{ Estriol } & t-value & p value \\
\hline D0* (day 0) & Mean & SD & Mean & SD & -1.4317 & 0.1559 NS \\
\hline 1 month & 24.26 & 2.82 & 25.26 & 3.87 & 1.5251 & $0.1309 \mathrm{NS}$ \\
\hline 3 months & 15.23 & 2.51 & 14.32 & 3.23 & 1.7507 & $0.0836 \mathrm{NS}$ \\
\hline 6 months & 10.21 & 2.34 & 9.21 & 3.14 & 1.3714 & $0.1736 \mathrm{NS}$ \\
\hline
\end{tabular}

*D0 (day 0) means at the start of therapy.

- G0-grade-0 $(0 \%)$

- G1-grade-1 (25\%)

- G2-grade-2 (50\%)

- $\mathrm{G} 3$-grade-3 (75\%)

- $\mathrm{G} 4$-grade-4 (100\%)

In this study the mean baseline KPI was $9.38 \pm 4.95$ and $8.26 \pm 4.94$ in Group I and Group II respectively and the difference was statistically not significant with t-value of 1.1325 and $\mathrm{p}$ value of 0.2602 . After 1 month of therapy, mean KPI was $10.88 \pm 7.77$ and $12.88 \pm 6.79$ in Group I and Group II respectively and the difference was statistically not significant with t-value of -1.3705 and $p$ value of
0.1737. After 3 months of therapy, mean KPI was $23.42 \pm 15.84$ and $24.84 \pm 14.58$ in Group I and Group II respectively and the difference was statistically not significant with t-value of -0.4664 and $p$ value of 0.642 . After 6 months of therapy, mean KPI was 33.92 \pm 15.84 and $36.86 \pm 15.05$ in Group I and Group II respectively 0.3311 .

In this study, baseline endometrial thickness was $3 \mathrm{~mm}$ in 12 patients of Group I and 10 patients of Group II, $4 \mathrm{~mm}$ was in 3 patients of Group I and 8 patients of Group II, NA in 35 patients of Group I and 32 patients of Group II. At 1-month endometrial thickness was $3 \mathrm{~mm}$ in 12 patients of Group I and 10 patients of Group II, $4 \mathrm{~mm}$ 
was in 3 patients of Group I and 8 patients of Group II. At 3 months, endometrial thickness was not changed in both the groups. At 6 months also endometrial thickness remained unchanged in both the groups.

Table 2: Distribution of cases according to grading for relief of vaginal symptoms.

\begin{tabular}{|c|c|c|c|c|c|c|c|c|c|c|}
\hline \multirow{3}{*}{$\begin{array}{l}\text { Duration } \\
\text { of therapy }\end{array}$} & \multicolumn{5}{|c|}{ Estradiol valerate $(\mathbf{N}=\mathbf{3 4})$} & \multicolumn{5}{|c|}{ Estriol $(\mathbf{N}=\mathbf{3 4})$} \\
\hline & G0 & G1 & G2 & G3 & G4 & G0 & G1 & G2 & G3 & G4 \\
\hline & No. $(\%)$ & No. $(\%$ & No. $(\%)$ & No. $(\%)$ & No. (\%) & No. $(\%)$ & No. $(\%)$ & No. (\%) & No. (\%) & No. (\%) \\
\hline & $6(17.65)$ & $1(2.94)$ & $5(14.71)$ & $11(32.35)$ & $8(23.53)$ & $8(23.53$ & $2(5.88)$ & $5(14.71)$ & $8(23.53)$ & $11(32.35)$ \\
\hline $3 \mathrm{~m}$ & - & - & $4(11.76)$ & $15(44.12)$ & $15(44.12)$ & - & - & $1(2.94)$ & $16(47.06)$ & $17(50.00)$ \\
\hline 6 months & - & - & - & $3(8.8)$ & $31(91.17)$ & - & - & - & $2(5.88)$ & $32(94.12)$ \\
\hline
\end{tabular}

Table 3: Distribution of cases according to KPI (Karyopyknotic Index).

\begin{tabular}{|llllll|l|}
\hline \multirow{2}{*}{ KPI } & Estradiol $(\mathbf{N}=\mathbf{5 0})$ & \multicolumn{2}{l|}{ Estriol $(\mathbf{N}=\mathbf{5 0})$} & t-value & p value \\
\hline *day 0 & Mean & SD & Mean & SD & & \\
\hline 1 month & 9.38 & 4.95 & 8.26 & 4.94 & 1.1325 & $0.2602 \mathrm{NS}$ \\
\hline 3 months & 10.88 & 7.77 & 12.88 & 6.79 & -1.3705 & $0.1737 \mathrm{NS}$ \\
\hline 6 months & 23.42 & 15.84 & 24.84 & 14.58 & -0.4664 & $0.642 \mathrm{NS}$ \\
\hline
\end{tabular}

Table 4: Distribution of cases according to endometrial thickness (ET) on trans vaginal sonography.

\begin{tabular}{|lllllll|}
\hline & \multicolumn{2}{c}{ Estradiol $(\mathbf{N}=\mathbf{5 0}) \mathbf{E T}$} & \multicolumn{2}{c|}{ Estriol $(\mathbf{N}=\mathbf{5 0}) \mathbf{E T}$} \\
\hline & $\mathbf{3} \mathbf{~ m m}$ & $\mathbf{4} \mathbf{~ m m}$ & $\mathbf{N A}$ & $\mathbf{3} \mathbf{~ m m}$ & $\mathbf{4} \mathbf{~ m m}$ & NA \\
\hline 0 day & 12 & 3 & 35 & 10 & 8 & 32 \\
\hline 1 month & 12 & 3 & 35 & 10 & 8 & 32 \\
\hline 3 months & N.C & N.C & 35 & N.C & N.C & 32 \\
\hline 6 months & N.C & N.C & 35 & N.C & N.C & 32 \\
\hline
\end{tabular}

NA: not applicable, NC: not changed.

\section{DISCUSSION}

In our study significant improvement in incontinence was seen after estrogen therapy. AUA (American Urological Association) Score has been decreased that is from base line mean value of 22.26 to 3.62 after 6 months of therapy in Group A and from 23.26 to 3.26 in Group B that shows over all symptomatic relief for urinary symptoms but no significant difference present between two groups. Fantl JA; Cardozo L; McClish DK et al (1994) Meta-analysis found similar results. ${ }^{6}$

After 1 month of therapy complete relief in genital symptoms was attained by $23.53 \%$ patients $(n=8)$ in Group I and $32.35 \%$ patients $(n=11)$ in Group II. After 3 month of therapy complete relief was attained by $44.12 \%$ patients $(n=15)$ in Group I and 50\% patients $(n=17)$ in Group II. After 6 months of therapy complete relief was attained by $91.17 \%$ patients $(n=31)$ in Group I and $94.12 \%$ patients $(n=32)$ in Group II. This is similar to Manonai J et al. ${ }^{7}$

In this study the mean baseline KPI was $9.38 \pm 4.95$ and $8.26 \pm 4.94$ in Group I and Group II respectively and the difference was statistically not significant with t-value of 1.1325 and $p$ value of 0.2602 . After 6-month of therapy, the increase in mean KPI was $33.92 \pm 15.84$ and $36.86 \pm 15.05$ in Group I and Group II respectively 0.3311 and the difference was statistically insignificant $t$ value of -0.9767 and $p$ value of 0.33 . Results were comparable to Maturitas et al. ${ }^{8}$

In this study, baseline endometrial thickness was $3 \mathrm{~mm}$ in 12 patients of Group I and 10 patients of Group II, $4 \mathrm{~mm}$ was in 3 patients of Group I and 8 patients of Group II. At 6 months endometrial thickness was not changed in 15 patients of Group I and 18 patients of Group II. This is similar to Wellington K, Perry CM et al. ${ }^{1,9}$

All these side effects were of not much significance with regards to the beneficial effects of either drugs. This is similar to Fugh-Berman et al. ${ }^{10}$

\section{CONCLUSION}

We can conclude that oral estradiol tablet and estriol vaginal cream are equally effective in alleviating the urogenital symptoms with no significant side effects.

Funding: No funding sources

Conflict of interest: None declared 
Ethical approval: The study was approved by the Institutional Ethics Committee

\section{REFERENCES}

1. Research on the Menopause in the 1990s. Report of a WHO Scientific Group. World Health Organization, WHO Technical Report Series No.866; 1996.

2. Portman DJ, Gass ML. Genitourinary syndrome of menopause: new terminology for vulvovaginal atrophy from the International Society for the Study of Women's Sexual Health and the North American Menopause Society. Menopause. 2014;21:1063-8.

3. Wilbush J. La menopause - the birth of a syndrome. Maturitas. 1979;1:145-51.

4. Stearns VS, Ollmer L, Lopez JF, Smith Y, Isaacs C, Hayes DF. Hot flushes. Lancet. 2002;306:1851-61.

5. Dennerstein L, Dudley EC, Hopper JL, Guthrie JR, Burger HG. A prospective population - based study of menopausal symptoms. Obstet Gynecol. 2000;96(3):351-8.

6. Fantl JA, Cardozo L, McClish DK. Estrogen therapy in the management of urinary incontinence in postmenopausal women: a meta-analysis. First report of the hormones and urogenital therapy committee. Obstet Gynecol. 1994;83:12-8.

7. Manonai J, Chittacharoen A, Theppisai U. Effect of estradiol valerate and levonorgestrel on vaginal health. Eur J Obstet Gynecol Reprod Biol. 2004;115(2):190-3.

8. Mattsson LA, Cullberg G, Eriksson O, Knutsson F. Vaginal administration of low-dose oestradiol-effects on the endometrium and vaginal cytology. Maturitas. 1989;11(3):217-22.

9. Wellington K, Perry CM. Estradiol valerate/dienogest. Drugs. 2002;62(3):491-504; discussion 505-6.

10. Fugh-Berman A, Bythrow J. Bioidentical hormones for menopausal hormone therapy: variation on a theme. Journal of general internal medicine. $2007 \mathrm{Jul}$ $1 ; 22(7): 1030-4$.

Cite this article as: Kumari S, Singh M. Compare the efficacy, safety and compliance of oral estradiol and vaginal estriol for urogenital problems in postmenopausal women. Int J Reprod Contracept Obstet Gynecol 2020;9:1186-90. 